\title{
Hubungan Kecepatan Reaksi Tangan dan Koordinasi Mata Tangan Pada Servis Tenis Lapangan Mahasiswa Universitas Cenderawasih
}

\author{
Kurdi ${ }^{\bowtie}$, Rif'iy Qomarrullah \\ Jurusan Ilmu Keolahragaan, Fakultas Ilmu Keolahragaan, Universitas Cenderawasih, Indonesia
}

\section{Info Artikel}

\section{Kata Kunci:}

Koordinasi, permainan, reaksi, servis, tenis.

\section{Keywords:}

Coordination, games, reaction, service, tennis.

\footnotetext{
Alamat korespondensi: J1. Kambolker Perumnas III, Yabansai, Heram, Kota Jayapura, Papua 99224

E-mail: kurdimr18@gmail.com
}

\begin{abstract}
Abstrak
Penelitian ini memiliki tujuan untuk menguji hubungan kecepatan reaksi pada teknik servis dalam permainan tenis lapangan dan koordinasi mata tangan pada teknik servis dalam permainan tenis lapangan. Penelitian menggunakan penelitian kuantitatif deskriptif. Partisipan dalam penelitian adalah seluruh mahasiswa S1 IKOR FIK Uncen angkatan 2018 yang berjumlah 49 orang. Instrumen penelitian menggunakan ruler drop test, tes koordinasi mata tangan, dan tes ketepatan pukulan servis. Teknik analisis data menggunakan uji korelasi. Hasil penelitian menyatakan hubungan kecepatan reaksi tangan pada ketepatan servis menunjukkan korelasi yang sangat kuat dan hubungan koordinasi mata tangan pada ketepatan servis menunjukkan korelasi yang rendah. Perlu penyelidikan lebih lanjut terkait dengan perbedaan temuan penelitian dengan peneltian terdaulu.
\end{abstract}

\begin{abstract}
This study aims to examine the relationship between reaction speed in service techniques in playing tennis and eye hand coordination in service techniques in playing tennis. The study uses descriptive quantitative research. Participants in the study were all students of IKOR FIK Uncen 2018 class of 49 people. The research instrument uses the ruler drop test, hand eye coordination test, and service puncture accuracy test. The data analysis technique uses correlation test. The results of the study stated that the correlation between hand reaction speed and service accuracy showed a very strong correlation and the correlation of hand eye coordination on service accuracy showed a low correlation. Need further investigation related to differences in research findings with earlier research.
\end{abstract}




\section{PENDAHULUAN}

Olahraga banyak dilakukan manusia untuk memenuhi aktivitas gerak seperti saluran edukatif, rekreatif, maupun prestatif. Sebagai saluran edukatif, olahraga menjadi media pendidikan dengan ditanamkannya kejujuran, kedisiplinan, dan nilai budaya hidup sehat. Sebagai saluran rekreatif, yakni olahraga merupakan transmisi kebahagiaan dalam memeroleh kesenangan terhadap pelaku dan penikmatnya. Sebagai saluran prestatif, dengan berolahraga secara profesional dengan kemahiran tinggi maka tercipta kompetisi antar pelakunya. Tiga hal tersebut diberikan secara lengkap dalam mata kuliah teori praktik tenis lapangan.

Mata kuliah tenis lapangan diberikan dalam rangka memberikan bekal kecakapan mahasiswa S1 Ilmu Keolahragaan (IKOR) Fakultas Ilmua Keolahragaan (FIK) Universitas Cenderawasih (Uncen). Kecakapan ini meliputi: (1) Keterampilan permaianan; (2) Pengetahuan perwasitan; dan (3) Manajemen pertandingan. Berkaitan dengan keterampilan bermain, hal utama yang perhatian yakni modal skill dan fisik. Kemampuan sangat berhubungan dengan teknik dan taktik yang harus dikuasai dengan ditunjang komponen fisik terkait yakni keadaan biomotor.

Komponen biomotor yang dianggap penting adalah kecepatan reaksi tangan dan koordinasi mata tangan. Terdapat dua macam istilah yakni kecepatan reaksi dan kecepatan gerak (Akbar, dkk, 2015:47). Kecepatan reaksi yaitu daya upaya yang berkaitan dengan rangsang dalam waktu relatif cepat. Koordinasi merupakan komponen pendudukung keterampilan teknik permainan tenis lapangan (Nugroho, 2011:22). Keterampilan permainan tenis lapangan tediri atas: servis, blocking, dan smash (Prasetiono dan Gandasari, 2018:221). Berdasarkan aturan resmi dari ITF (International Law-Tenis Federation) lapangan tenis berukuran panjang 23,77 meter (m), kemudian lebar berukuran 10,97 $\mathrm{m}$, dan jarak garis net dengan servis adalah 6,40m (Irawan, dkk, 2017:2).

Fasilitas permainan tenis lapangan yang digunakan yakni raket dan bola bundar dengan lapisan karet dan dapat memantul dengan cepat.
Oleh karenanya, ketepatan memukul dan menempatkan bola menjadi sangat penting dalam permainan tenis lapangan. Ketepatan menempatkan bola juga menjadi indikator keberhasilan teknik yang dilakukan. Pemain dengan kecepatan reaksi tangan dan koordinasi mata tangan yang mempunyai performa tinggi dalam setiap permainan. Tantangan yang dihadapi peneliti pada mata kuliah tenis lapangan hampir rata-rata mahasiswa baru mengenal permainan ini dalam pembelajaran yang memungkin belum diketahuinya kecepatan reaksi tangan dan koordinasi mata tangan dari setiap mahasiswa yang mengiktui mata kuliah tenis lapangan.

Beberapa peristiwa penting dalam sebuah pertandingan tenis lapangan dunia patut menjadi contoh, misalnya bagaimana Rafael Nadal menjadi juara dunia, bagaimana Sherena Williams menjadi petenis putri terbaik diajang internasional. Indonesia pernah memiliki Yayuk Basuki dan Angelik Wijaya yang dapat berbicara dalam turnamen-turnamen internasional. Hal menarik yang bisa diungkap dari rangkaian cerita kesuksesan tersebut adalah bahwa tenis lapangan merupakan olahraga permainan dengan akurasi dan intuisi yang terlatih, disamping pula harus ditopang dengan kemampuan fisik dan kecerdikan gerak yang trengginas. Servis dalam permainan tenis adalah sangat menentukan apa jalannya permainan, pemain yang sering melakukan kesalahan pada proses ini umumnya cenderung akan mengalami ketidak percayaan diri. Kemudian berakibat kepada konsentrasi dan koordinasi yang tidak berimbang.

Sebuah penelitian dapat menjadi bukti yang nyata untuk merubah persepsi tersebut. Kecepatan reaksi dan koordinasi mata-tangan adalah komponen biomotor yang dibutuhkan dalam permainan tenis lapangan. Sedangkan ketepatan pukulan adalah kemampuan (skill) yang harus dikuasai dalam permainan tenis lapangan. Belum dilakukan riset ilmiah apakah kecepatan reaksi tangan dan koordinasi mata tangan yang baik apakah memberikan sumbangan terhadap presisi pukulan dalam permainan tenis lapangan. Hal itu yang 
melatarbelakangi peneliti merumuskan hasil kajian terkait berapa nilai sumbangan kecepatan reaksi tangan dan koordinasi mata tangan terhadap ketepatan pukulan servis pada permainan tenis lapangan. Selanjutnya hasil riset yang dilaksanakan dapat memberikan informasi ilmiah terhadap atlet/ pelatih, dan sebagai referensi penentuan program latihan yang baik. Adapun dalam pelaksanaannya, peneliti membatasi ruang lingkup penelitian agar tidak terlalu luas dan lebih akurat dalam pelaksanaannya. Pembatasan masalah dalam penelitian ini yakni berkaitan hubungan kecepatan reaksi pada teknik servis dalam permainan tenis lapangan dan koordinasi mata tangan pada teknik servis dalam permainan tenis lapangan.

\section{METODE}

Penelitian yang telah dilaksanakan berpedoman pada kaidah-kaidah penelitian kuantitatif deskriptif korelasional. Penelitian ini dilakukan untuk mengkaji hubungan antara dua variabel. Kecepatan reaksi tangan pada kemampuan teknik servis dan koordinasi mata tangan pada kemampuan teknik servis.

\section{Partisipan}

Partisipan dalam penelitian adalah seluruh mahasiswa S1 IKOR FIK Uncen angkatan 2018 , adapun sampel yang digunakan berjumlah 49 orang yang terdiri dari 30 laki-laki dan 19 perempuan dengan menggunakan teknik purposive sampling. Pelaksanaannya sendiri adalah dilakukan pada Mei tahun 2020 di lapangan tenis Universitas Cenderawasih Padang Bulan Kampus Distrik Abepura Kota Jayapura Provinsi Papua Indonesia.

\section{Instrumen}

Instrumen pengambilan data yang peneliti gunakan adalah teknik tes yang meliputi: ruler drop test (Anindita, dkk, 2017:263) untuk mengukur kecepatan reaksi tangan, tes koordinasi mata tangan (Ahwdi, dkk, 2016: 38) untuk mengukur koordinasi mata tangan, dan tes ketepatan pukulan servis (Maulidin, 2017: 318).

\section{Prosedur}

Untuk mencapai keberhasilan dalam melakukan sebuah penelitian maka diperlukan sebuah data untuk kemudian dianalisis. Penelitian ini untuk memperoleh data dilakukan dengan tiga kali tes berkaitan dengan kecepatan reaksi tangan, koordinasi mata tangan, dan tes ketepatan pukulan servis.

\section{Analisis Data}

Untuk teknik analisis dengan menggunakan uji korelasi dengan bantuan SPSS 20.0.

\section{HASIL}

Statistik deskriptif data hasil dari tes kecepatan reaksi tangan (KRT), tes koordinasi matatangan (KMT), dan tes ketepatan servis (KTS) dapat di lihat pada Tabel 1.

Tabel 1. Deskripsi Data

\begin{tabular}{cccc}
\hline Statistik & KRT & KMT & KTS \\
\hline Mean & 1,37 & 6,16 & 10,449 \\
Standar Deviasi & 0,28 & 1,34 & 3,130 \\
Nilai Tertinggi & 2,18 & 9,00 & 19,00 \\
Nilai Terendah & 0,87 & 4,00 & 5,00 \\
\hline
\end{tabular}

Sebelum melakukan uji korelasi dikarenakan data belum berupa angka bulat. Maka peneliti menggunakan $\mathrm{T}$ skor. $\mathrm{T}$ skor dalam penelitian ini berguna untuk menstandarkan dan mengonversi satuan waktu serta nilai kumulatif tes. Hasil perhitungan uji korelasi dapat dilihat pada Tabel 2

Tabel 2. Uji Korelasi

\begin{tabular}{cccc}
\hline Statistik & $\mathrm{r}_{\text {hitung }}$ & $\mathrm{r}_{\text {tabel }}$ & Hasil \\
\hline KRT & 0,980 & 0,276 & Signifikan \\
KMT & 0,325 & 0,276 & Signifikan \\
\hline
\end{tabular}

\section{PEMBAHASAN}

Pembahasan penelitian ini digunakan untuk menganalisis hubungan KRT pada KTS dan KMT pada KTS. Hubungan KRT pada KTS menunjukkan nilai korelasi yang signifikan yang dibandingkan dengan nilai $r_{\text {tabel. }}$. Hasil ini memiliki keterkaitan dengan penelitian Filipčič, dkk (2017:117) bahwa kecepatan reaksi tangan 
memberikan sokongan pukulan servis dan smash dalam permainan tenis lapangan. Riset lain juga terdapat hubungan dengan penelitian Mavvidis, dkk (2014:576) yakni genggaman grip raket yang baik dan konsentrasi berkorelasi dengan kecepatan reaksi tangan saat menerima umpan servis dalam tenis lapangan. Hasil penelitian ini memberikan temuan baru dan menambah referensi yang sudah ada bahwa KRT memberikan hasil yang mendekati hubungan yang sempurna pada KTS. Bila melihat pada interprestasi korelasi berada pada tingkat hubungan yang sangat tinggi.

Tenis lapangan merupakan permainan olahraga yang sangat dinamis, ritme gerakannya sangat bergantung pengendalian indera. Permainan ini bergantung pantulan bola yang datang, sehingga diperlukan fisik prima. Komponen fisik menjadi prasyarat utama yang dibutuhkan oleh pemain tenis, dan kecepatan reaksi tangan satu diantaranya yang diperlukan. Menurut Permatasari, dkk (2016: 14) dinyatakan jika kemampuan atlet dalam menerima tindakan balik berupa bola dari lawan dengan gerak fungsional cermat merupakan kecepatan reaksi tangan dan raket. Oleh sebab itu, apabila pemain tenis dapat memiliki waktu reaksi yang efisien sudah barang tentu akan menerima stimulus respon dengan cepat.

Reaksi dibedakan menjadi dua, yaitu: autonom dan multiple (Kuan, 2018:136). Autonom reaction muncul dari pemain untuk menanggapi rangsangan dengan arah yang sudah diketahui sebelumnya dengan waktu hight-repetitif dan multiple reaction muncul dari pemain untuk menanggapi rangsangan dengan arah tidak terduga sebelumnya dengan tinggi (Syafitri, dkk, 2017:178; Cahyadi, dkk, 2019:69). Kecepatan reaksi tangan dalam tenis dapat tergolong multiple reaction sebab tangan merupakan mengeksekusi bola yang datang dari arah berlawanan (Nuri, dkk, 2012: 2).

Kecepatan reaksi tangan diperlukan dalam permainan tenis sebab setiap datangnya bola tidak dapat diprediksi, justru setiap pemain akan beruapaya mengarahkan bola jauh dari jangkauan lawan. Setiap laju bola yang cepat dan terarah memerlukan daya antisipasi yang baik, gerak inilah yang dikategorikan dalam multiple reaction. Apabila pemain tidak memiliki kemampuan yang memadai untuk siap siaga dalam menerima dan menempatkan bola dengan cermat, maka kesalahan akan terjadi dan dapat menurunkan performa fisik. Umumnya yang terjadi adalah terlambatnya pemain memberikan respon stimulus pada saat bola datang, dan mengembalikan dengan tanpa kontrol gerak yang baik, sehingga bola sering tidak dapat melewati net atau bahkan melambung jauh tanpa arah kendali.

Secara spesifik dapat disimpulkan bahwa, kecepatan reaksi tangan merupakan daya sigap seseorang dalam menerima rangsangan gerak yang datang secara cepat, mendadak dengan arah yang berlawanan dan secepat mungkin tangan memberikan tanggapan dalam reaksi gerak tersebut dalam permainan tenis yang sangat dinamis.

Hubungan KMT pada KTS menunjukkan nilai korelasi yang signifikan yang dibandingkan dengan nilai $\mathrm{r}_{\text {tabel. }}$. Koordinasi dalam permaianan tenis lapangan memberikan arti secara spesifik bahwa gerak yang dilakukan secara terpadu melibatkan receiver indera stimulus badan dan kaki, serta tangan sebagai komponen artivisial gerak. Kemudian, secara khusus dapat dijelaskan bahwa koordinasi mata tangan adalah koordinasi sensorik gerak dari mata untuk melangsungkan pesan transmisi ke otak dan dieksekusi oleh gerakan tangan yang selanjutnya mempresisi gerak itu dengan baik.

Hasil penelitian yang telah dilaksanakan memiliki relevansi dengan riset Syafrudin (2019:30) yang menyatakan jika koordinasi mata tangan memberikan yang baik dapat memberikan manfaat dalam kemampuan pukulan servis olahraga permainan yang menggunakan organ tubuh dibagian tangan. Senada dengan hasil tersebut, Pramahardika (2014:171) dalam risetnya diperoleh data jika koordinasi mata tangan memberikan sumbangan 90,82 \% terhadap pukulan forehand groundstroke tenis lapangan. Oleh karenanya, dapat dipahami bahwa pengaruh yang ditimbulkan oleh koordinasi yang baik membawa dampak pada presisi pukulan servis 
tenis lapangan, sebab pemain tenis bergerak cepat, trengginas dan dinamis dalam mencapai maupun mendapati pukulan bola yang tidak dapat dipastikan arahnya selalu sama. Berbeda dengan hasil penelitian Pramahardika (2014:171) yang mengarah kepada hasil pukulan forehand groundstroke tenis lapangan, hasil penelitian yang mengarah kepada ketepatan servis menyatakan bahwa hubungan KMT pada KTS memberikan hasil yang signifikan tetapi bila melihat interprestasi korelasi berada pada tingkat hubungan yang rendah. Maka penelitian ini memberikan saran agar lebih mengkaji lebih dalam berkaitan dengan KMT pada KTS. Temuan ini dapat dijadikan referensi baru dengan pertanyaan penelitian apakah benar KMT pada KTS berada dalam tingkat hubungan yang rendah sedangkan KMT pada pukulan forehand groundstroke memiliki sumbangan kontribusi yang sangat kuat.

Tenis lapangan adalah permainan yang cukup kompleks dimana dalam setiap pukulan baik smash ataupun servis diperlukan latihan yang kontinyu dan berjenjang. Teknik, taktik dan fisik yang diperoleh pemain tenis dapat dipadukan apabila terdapat koordinasi yang rapi dalam diri pemain itu sendiri. Mahasiswa peserta mata kuliah tenis lapangan telah memiliki modal koordinasi mata-tangan, hal ini dapat menjadikan modal bagi mereka untuk terus mengasah kemampuan dan meningkatkan keterampilan bermain tenis lapangan diluar jamjam perkuliahan untuk menambah porsi latihan secara mandiri.

Koordinasi memiliki arti penting dimana koordinasi tubuh yang baik akan membuat gerakan yang beragam menjadi seimbang, efisien serta efektif. Koordinasi secara spesifik dalah mempergunakan beberapa anggota tubuh, dimana kombinasi akurasi pukulan tangan dengan langkah kaki. Koordinasi mata tangan dengan langkah kaki ini termasuk dalam koordinasi gerak khusus. Tangan dalam permainan tenis menjadi alat gerak dominan yang berfungsi sebagai alat pemukul, akan tetapi mata berfungi sebagai reseptor penerima.

\section{KESIMPULAN}

Berdasarkan hasil analisis data dapat diambil kesimpulan bahwa hubungan kecepatan reaksi tangan pada ketepatan servis menunjukkan korelasi yang sangat kuat dan hubungan koordinasi mata tangan pada ketepatan servis menunjukkan korelasi yang rendah. Secara umum penelitian ini dipandang memiliki kebermanfaatan bagi dosen, mahasiswa, pelatih, dan atlet dalam mereposisi program-program latihan yang efektif dan tepat. Adapun faktorfaktor lain yang turut memiliki pengaruh mungkin seperti motivasi, kepribadian, lingkungan, ataupun tingkat kecerdasan. Peneliti memberikan saran agar melakukan penelitian lebih lanjut terkait dengan hasil perbedaan temuan yang menyatakan bahwa koordinasi mata tangan pada ketepatan servis berada dalam tingkat hubungan yang rendah sedangkan koordinasi mata tangan pada pukulan forehand groundstroke memiliki sumbangan kontribusi yang sangat kuat.

\section{UCAPAN TERIMAKASIH}

Terima kasih penulis ucapkan kepada Dekan FIK Uncen dan Ketua Jurusan IKOR FIK Uncen serta mahasiswa yang telah berpartisipasi dalam penelitian.

\section{REFERENSI}

Ahwadi, Luby Tsani. Yudiana, Yunyun. Kusmaedi, Nurlan. (2016). "Hubungan Koordinasi Mata dan Tangan dengan Hasil Tangkapan Bola Lambung Infield, Outfield Pada Cabang Olahraga Softball". Jurnal Terapan Ilmu Keolahragaan. ISSN 2549-6360. 1 (1) 3743.

Akbar, Ali. Saifuddin. Mansur. (2015). "Evaluasi Unsur Kelincahan dan Kecepatan Reaksi Otot Tangan Atlet Tarung Derajat Binaan Satlat Unsyiah Tahun 2013". Jurnal Ilmiah PJKR FKIP Unsyiah. ISSN: 2548-4605. 1 (1) 45-53.

Anindita, Amitya Ekacitta. Sumekar, Tanjung Ayu. Supatmo, Yuswo. (2017). "Analisis Komponen Waktu Reaksi Atlet Bulutangkis (Studi pada Atlet Bulutangkis di Semarang)". Jurnal Kedokteran Diponegoro. ISSN: 25408844. 6 (2) 261-267. 
Filipčič, Aleš. Leskošek, Bojan. Munivrana, Goran. Ochiana, Gabriel. Filipčič, Tjaša. (2017). "Differences in Movement Speed Before and After a Split-Step Between Professional and Junior Tennis Players". Journal of Human Kinetics. ISSN: 1640-5544. 55 (1) $117-125$.

Irawan, Ricko. Nurharsono, Tri. Raharjo, Agus. (2017). "Pengembangan Produk Permainan Mikro Tenis Sebagai Alternatif Keterbatasan Ketersediaan Fasilitas Lapangan Tenis ". Jurnal Pendidikan Jasmani. ISSN: 0852-8322. 29 (2) $1-7$.

Maulidin. (2017). "Hubungan Power Otot Lengan dan Kekuatan Genggaman Dengan Hasil Servis Slice pada Permainan Tenis Lapangan pada Mahasiswa FPOK IKIP Mataram Tahun 2017". Jurnal Ilmiah Mandala Education. ISSN: 2442-9511. 3 (1) 314325.

Mavvidis A. Manousaridou A. Grivas N. Evagelidis T. Laios A. (2014). "The Effectiveness of Serve in Tennis Depending on The Placement of Palm Across The Racket Grip Inwards or Outwards. Journal of Physical Education and Sport (JPES). ISSN: 2247-8051. 14 (4) $576-580$.

Nugroho, Prapto. (2011). "Latihan Backhand Volley dari Bola Groundstroke dengan Figure Eight Volley dan Kemampuan Penempatan Backhand Volley pada Petenis Pemula". Jurnal Media Ilmu Keolahragaan Indonesia. ISSN: 20886802. 1 (1) 22-27.

Nuri, Leila. Shadmehr, Azadeh. Ghotbi, Nastaran. Attarbashi, Behrouz. Moghadam. (2012). "Reaction Time and Anticipatory Skill of Athletes in Open and Closed Skill-Dominated Sport". European Journal of Sport Science. ISSN: 1746-1391. 10 (1) 1-6.

Permatasari, Niluh Ketut Nita. Rusdiana, Agus. Ruhayati, Yati. (2016). "Pengembangan Alat Ukur Waktu Reaksi Berbasis Microcontroller". Jurnal Terapan Ilmu Keolahragaan. ISSN: 2549-6360. 1 (1) 13-17.

Pramahardika, Angga Nur. (2014). "Kontribusi Kekuatan Otot Lengan dan Koordinasi Mata Tangan Terhadap Forehand Groundstroke Tenis Lapangan". Jurnal Kesehatan Olahraga. ISSN: 2338-8005. 2 (2) 164-172.
Prasetiono, Beni Agus. Gandasari, Maharani Fatimah. (2018). "Model Rangkaian Tes Keterampilan Tenis Lapangan Pada Pemain Putra Kelompok Usia 1214 Tahun". Jurnal SPORTIF : Jurnal Penelitian Pembelajaran. ISSN: 25487833. 4 (2) 220-234.

Syafitri, Aisyah Winda. Supatmo, Yuswo. Indraswari, Darmawati Ayu. (2017). "Perbedaan Waktu Reaksi Tangan Antara Cabang Olahraga Permainan dan Bela Diri". Jurnal Kedokteran Diponegoro. ISSN: 2540-8844. 6 (2) 177 187.

Syafruddin, Muhammad Akbar. (2019). "Pengaruh Struktur Tubuh dan Koordinasi Mata Tangan Terhadap Kemampuan Passing Bawah Dalam Permainan Bola Voli Atlet Kota Makassar". Jendela Olahraga. ISSN: 2527-9580. 4 (2) 30-36. 